\title{
Characterization of Anaplasma ovis strains using the major surface protein 1a repeat sequences
}

Rong Han ${ }^{1,2+}$, Jifei Yang ${ }^{1 \dagger}$, Zhijie Liu', Shaodian Gao', Qingli Niu', Muhammad Adeel Hassan', Jianxun Luo ${ }^{1}$ and Hong Yin ${ }^{1,3^{*}}$

\begin{abstract}
Background: Anaplasma ovis is one of the tick-transmitted pathogens of small ruminants. It causes ovine anaplasmosis and widely distributed in the world. In contrast to extensive worldwide genetic diversity of $A$. marginale and A. phagocytophilum, there are few reports on the classification of A. ovis strains. This study was conducted to investigate the occurrence and characterize A. ovis strains from goats and sheep from 12 provinces in China.

Methods: The occurrence of A. ovis DNA was tested in 552 goats and sheep, by PCR based on the msp4 gene. Positive samples were used for the amplification of the mspla gene of A. ovis. The Mspla amino acid repeats were further identified and used for the characterization of $A$. ovis strains.

Results: The results showed that 79 (14.3\%) goats and sheep were positive for A. ovis. The infection rates of $A$. ovis among different study sites ranged from 0 to $100 \%$, and were significantly higher in sheep (26. $6 \%, 45 / 169)$ than in goats $(8.9 \%, 34 / 383)\left(X^{2}=21.403, d f=1, P<0.001\right)$. The msp4 gene sequences of these isolates were $99.8-100 \%$ identical to each other, and they represented two sequence types. Forty-four partial mspla gene sequences containing the repeat sequences were obtained from A. ovis-positive samples. After translation to amino acid sequences, 24 Msp1a repeats with 33 to 47 amino acids, which corresponded to 19 genotypes of A. ovis, were recognized in goats and sheep in China.

Conclusions: Anaplasma ovis is widely distributed in the investigated geographical regions. The msp4 gene of $A$. ovis had high sequence identity and was unable to be used to discriminate different strains. The Mspla could be used as a genetic marker for characterizing A. ovis, and 19 genotypes of A. ovis were recognized in domestic small ruminants in China. The present study revealed, for the first time, the genetic diversity of A. ovis based on the analyses of Msp1a amino acid repeats.
\end{abstract}

Keywords: Anaplasma ovis, msp4 gene, Msp1a repeats, Genotypes, Sheep, Goats, China

\footnotetext{
* Correspondence: yinhong@caas.cn

${ }^{\dagger}$ Equal contributors

'State Key Laboratory of Veterinary Etiological Biology, Key Laboratory of Veterinary Parasitology of Gansu Province, Lanzhou Veterinary Research Institute, Chinese Academy of Agricultural Sciences, Xujiaping 1, Lanzhou, Gansu 730046, People's Republic of China

${ }^{3}$ Jiangsu Co-innovation Center for Prevention and Control of Important Animal Infectious Diseases and Zoonoses, Yangzhou 225009, People's Republic of China

Full list of author information is available at the end of the article
} International License (http://creativecommons.org/licenses/by/4.0/), which permits unrestricted use, distribution, and reproduction in any medium, provided you give appropriate credit to the original author(s) and the source, provide a link to the Creative Commons license, and indicate if changes were made. The Creative Commons Public Domain Dedication waiver (http://creativecommons.org/publicdomain/zero/1.0/) applies to the data made available in this article, unless otherwise stated. 


\section{Background}

Anaplasma are obligate intracellular Gram-negative rickettsial bacteria of medical and veterinary interest in both tropical and subtropical regions [1]. The disease caused by Anaplasma spp. has been recognized over a century, and is still an important issue worldwide [2, 3]. Since disclosure of zoonotic potential of $A$. phagocytophilum in 1994, there has been great interest in these bacteria [1, 4]. Until recently, six species have been recognized in the genus Anaplasma: Anaplasma marginale, Anaplasma bovis, Anaplasma phagocytophilum, Anaplasma centrale (A. marginale centrale), Anaplasma platys and Anaplasma ovis [5]. Anaplasma carpa has recently been described and considered as an emerging zoonotic pathogen in China [6]. The members in the genus Anaplasma differ in their cellular tropism, vectors, host range and pathogenicity [5].

Ovine anaplasmosis is caused by $A$. ovis, which is an obligate intra-erythrocytic pathogen of small ruminants [5, 7]. The causative agent was first described in sheep in 1912, and is widely distributed in Asia, Africa, Europe and the USA [7, 8]. This organism infects sheep, goats and some wild ruminants [9, 10]. Recently, an $A$. ovis variant was detected in a patient in Cyprus, indicated the zoonotic potential of this agent [11]. The life-cycle of $A$. ovis involves vertebrates and ticks, and animals can develop persistent infections and serve as reservoir hosts [12].

Currently, the identification and characterization of A. ovis mainly relies on the analysis of $16 \mathrm{~S}$ rRNA and msp4 genes; however, these genes are highly conserved among heterologous strains [3, 13]. In previous reports, the major surface protein 1a (Msp1a), encoded by the msp1a gene, has been recognized as a stable molecular marker for classifying strains of $A$. marginale [14]. It has been revealed that $A$. marginale Msp1a could have evolved on the strength of immune selection pressure and differs among strains due to variable sequences and numbers of tandem amino acid repeats located in the $\mathrm{N}$-terminal region of the protein [15]. The repeated region of $A$. marginale Msp1a contains the adhesion domain for tick cells and erythrocytes, which is essential for the invasion and transmission of the organism [15]. Previous reports have reported that immunization of cattle with Msp1a induces partial protection when challenged with $A$. marginale $[15,16]$. Recently, Msp1a has also been identified in $A$. centrale, although attempts on other Anaplasma species have been performed [17]. In this study, we investigated the occurrence of $A$. ovis in small domestic animals in China, and identified the mspla gene from $A$. ovis-positive samples. The $A$. ovis isolates identified herein were subsequently characterized based on the Mspla amino acid repeats.

\section{Methods}

Sample collection and DNA preparation

Blood samples were obtained from March to September between 2011 and 2015 in 24 counties from 12 provinces of China (Table 1). Five hundred and fifty-two asymptomatic small ruminants (sheep, $n=169$; goats, $n=383$ ) were randomly selected in two to three sampling sites from each county included in this study. Blood samples were collected from the jugular vein of individual animals and collected in a sterile $10 \mathrm{ml}$ vacutainer EDTA tubes and stored at $4{ }^{\circ} \mathrm{C}$. DNA was prepared from $300 \mu \mathrm{l}$ of blood by using the Gentra Puregene Blood Kit (Qiagen, Beijing, China) following the manufacturer's instructions.

\section{PCR reactions}

Specific DNA of $A$. ovis was detected by PCR based on msp4 gene with primer set MSP45 (5'-GGG AGC TCC TAT GAA TTA CAG AGA ATT GTT TAC-3') and MSP43 (5' -CCG GAT CCT TAG CTG AAC AGA ATC

Table 1 Prevalence of A. ovis in goats and sheep from China, 2011-2015

\begin{tabular}{|c|c|c|c|c|}
\hline \multicolumn{2}{|l|}{ Location } & \multirow[t]{2}{*}{ Species } & \multicolumn{2}{|l|}{ No. infected } \\
\hline Province & Country & & No. tested & No. positive (\%) \\
\hline \multirow[t]{2}{*}{ Chongqing } & Wanzhou & Goat & 24 & $0(0)$ \\
\hline & Jiangjin & Goat & 30 & $0(0)$ \\
\hline \multirow[t]{2}{*}{ Guangxi } & Pingxiang & Goat & 11 & $0(0)$ \\
\hline & Jingxi & Goat & 19 & $0(0)$ \\
\hline \multirow[t]{2}{*}{ Guizhou } & Dushan & Goat & 17 & $4(23.5)$ \\
\hline & Rongjiang & Goat & 29 & $1(3.4)$ \\
\hline Hebei & Baoding & Sheep & 19 & $0(0)$ \\
\hline \multirow[t]{3}{*}{ Liaoning } & Haicheng & Goat & 23 & $1(4.3)$ \\
\hline & Huangren & Goat & 16 & $0(0)$ \\
\hline & Fengcheng & Goat & 14 & $0(0)$ \\
\hline Hainan & Haikou & Goat & 28 & $6(21.4)$ \\
\hline \multirow[t]{4}{*}{ Inner Mongolia } & Manzhouli & Sheep & 13 & $0(0)$ \\
\hline & Xinbaerhuzuoqi & Sheep & 20 & $14(70.0)$ \\
\hline & Aershan & Sheep & 20 & $4(20.0)$ \\
\hline & Eerguna & Goat & 20 & $5(25.0)$ \\
\hline \multirow[t]{2}{*}{ Sichuan } & Hejiang & Goat & 32 & $0(0)$ \\
\hline & Panzhihua & Goat & 31 & $13(41.9)$ \\
\hline Shanxi & Lvliang & Sheep & 50 & $22(44.0)$ \\
\hline \multirow[t]{2}{*}{ Guangdong } & Qingyuan & Goat & 30 & $0(0)$ \\
\hline & Zhaoqing & Goat & 33 & $0(0)$ \\
\hline \multirow[t]{3}{*}{ Yunnan } & Ruili & Goat & 4 & 4 (100) \\
\hline & Fuyuan & Goat & 7 & $0(0)$ \\
\hline & Yanshan & Goat & 15 & $0(0)$ \\
\hline Hubei & Suizhou & Sheep & 47 & 5 (10.6) \\
\hline Total & & & 552 & 79 (14.3) \\
\hline
\end{tabular}


TTG C-3') as described previously, which generated a product of 869 bp [13]. The DNA of $A$. ovis strain Haibei (GenBank accession no. GQ483471) and sterile water were used as the positive and negative control, respectively. Amplification products were analyzed by $1.0 \%$ agarose gel electrophoresis. The mspla gene was further amplified from $A$. ovis-positive samples. Primers AoMsplaF (5'-CGT TTC CAT GTG CTA CAA TGC CG-3') and AoMsplaR (5'-GCT GTT CGC TAT CGC AGT CTG TG-3') were designed based on the A. ovis strain Haibei genome sequence (GenBank accession no. CP007596, unreleased) to target repeat sequences within the mspla gene. The PCR reaction system is consistent with the amplification of $m s p 4$ gene. Thermal cycling conditions include $94{ }^{\circ} \mathrm{C}$ for $4 \mathrm{~min}, 35$ cycles at $94{ }^{\circ} \mathrm{C}$ for $30 \mathrm{~s}, 55{ }^{\circ} \mathrm{C}$ for $30 \mathrm{~s}$, and $72{ }^{\circ} \mathrm{C}$ for $30 \mathrm{~s}$, with a final extension step at $72{ }^{\circ} \mathrm{C}$ for $5 \mathrm{~min}$.

\section{Sequence and statistical analysis}

The amplified fragments of $m s p 4$ and mspla genes were purified and cloned into pGEM-T Easy vector (Promega, Madison, WI, USA). At least two recombinants were sequenced from each amplification (Genscript, Nanjing, China). The msp4 gene sequences have been deposited in GenBank (accession numbers KY807127 and KY807128) and were analyzed by the BLASTn search and the ClustalW software (DNAStar, Madison, WI, USA). The mspla gene sequences were edited and translated to amino acids by using CLC Genomics Workbench 7.5.1 (Qiagen, Aarhus, Denmark). The amino acid repeat sequences were identified and named Aon. These repeats were aligned using the ClustalV method in the MegAlign software. Statistical analysis was performed with a Chi-square test in Predictive for Analytics Software Statistics 18 (PASW, SPSS Inc., Chicago, IL, USA), and a difference was considered statistically significant at $P<0.05$.

\section{Results}

In total, 552 blood samples from goats and sheep were screened for the presence of $m s p 4$ gene of $A$. ovis. The results showed that $79(14.3 \%)$ sampled animals were positive for $A$. ovis (Table 1). The prevalence of $A$. ovis among different study regions ranged between 0 and $100 \%$, and were significantly higher in sheep $(26.6 \%, 45 /$ 169) than in goats $(8.9 \%, 34 / 383)\left(\chi^{2}=21.403, d f=1\right.$, $P<0.001$ ) (Table 1).

The $A$. ovis infections in goats and sheep were further confirmed by sequencing, and $42 \mathrm{msp} 4$ gene sequences were obtained. The msp 4 gene sequences shared 99.8$100 \%$ similarities, and they represented two sequence types. Eighteen msp4 sequences (13 from sheep and 5 from goats, GenBank accession no. KY807127) were identical to the strains Italy 147 and Yuzhong of A. ovis, which were detected in sheep from Italy and China
(GenBank: AY702924 and HQ456348, respectively) [18, 19]. The remaining $24 m s p 4$ sequences (8 from sheep and 16 from goats, GenBank: KY807127) have 99.9\% identity to the $A$. ovis strains ATS20, Yongjing and Italy 20 derived from sheep (GenBank: KJ782397, HQ456347 and AY702923) [18-20].

Forty-four partial mspla gene sequences contained the repeat sequences were obtained from $A$. ovis-positive samples. After translated to amino acid sequences, 24 different types of Msp1a repeats of $A$. ovis were identified and named Ao1-24 in this study (Fig. 1, partial mspla amino acid sequences are available in Additional file 1: Table S1). These Msp1a repeats were highly variable with 33 to 47 amino acids, and several positions (GQVS-_-_-_-VM-TSW

-ATPG-Q-QAS) were totally conserved (Fig. 1).

The structure of the Mspla repeats region was represented using the amino acid repeat types for isolates of $A$. ovis. Overall, 44 isolates of $A$. ovis were classified and resulted in 19 genotypes based on the organization of different amino acid repeats (Table 2). Aside from one isolate (A18-18a, Ao18/Ao19/Ao11) that had three amino acid repeats, the remaining 43 isolates contained two amino acid repeats (Table 2). Five of 24 Msp1a repeat sequences (Ao5, Ao6, Ao8, Ao10 and Ao11) were shared between different isolates. The repeat Ao6 was the most common repeat sequence, occurring in eight genotypes of 27 isolates (Table 2). However, most of the repeats had a low frequency, one time in only one strain (Table 2). According to the organization of Msp1a repeats in A. ovis isolates, ten genotypes (Ao1/Ao6, Ao2/Ao6, Ao3/Ao6, Ao5/ Ao6, Ao7/Ao6, Ao10/Ao8, Ao15/Ao16, Ao22/Ao6, Ao23/ Ao10, and Ao24/Ao5) were identified in goats and nine genotypes (Ao4/Ao6, Ao4/Ao11, Ao9/Ao10, Ao10/Ao13, Ao12/Ao8, Ao14/Ao8, Ao17/Ao6, Ao18/Ao19/Ao11, and Ao20/Ao21) were found in sheep.

\section{Discussion}

Ovine anaplasmosis is widely distributed and causes mild clinical symptoms [21]. Anaplasma ovis was first described in sheep as early as 1982 in Xinjiang Uygur Autonomous Region, and it was subsequently detected in goats in Liaoning province in China [22]. After that, several molecular epidemiological investigations of $A$. ovis have been conducted in domestic and wild ruminants from different geographical locations [23]. In those reports, $A$. ovis was found in 88 of 621 sheep (14.2\%) and in 129 of 710 goats (18.2\%) from six provinces [24]; in 51 of 125 sheep (40.5\%) from Xinjiang [20]; and in goats from Henan (8.7\%), Hubei (7.2\%), Guizhou (17.8\%) and Zhejiang (26.3\%), with an overall prevalence of 15.3\% (40/262) [25]. Apart from domestic ruminants, $A$. ovis has also been found in mongolian gazelle (Procapra gutturosa) (48/92, 52.2\%) [10], red deer (Cervus elaphus) 


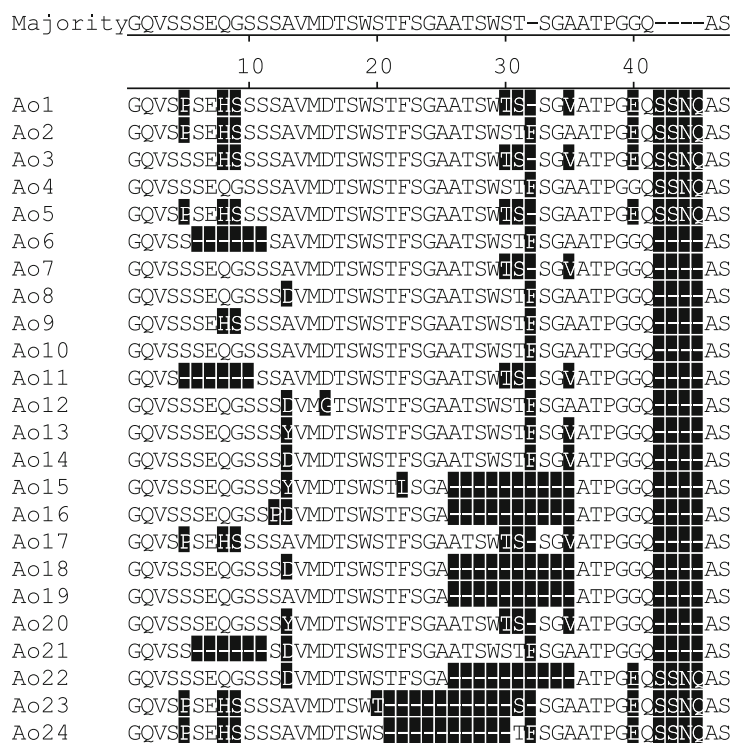

Fig. 1 The Mspla amino acid repeat sequences of A. ovis geographical strains identified from goats and sheep. The ID of each repeat type was named as Ao1-24, which were aligned using the ClustalV method in the MegAlign software. The one letter code was used to reveal the different amino acid sequences of Mspla repeats. The variable amino acids are highlighted on a black background and gaps indicate deletions/insertions

(14/44, 32.0\%), sika deer (Cervus nippon nippon) (8/40, 20.0\%) [9], and dogs $(6.1 \%, 15 / 243)$ [26]. Moreover, the DNA of $A$. ovis has been detected in milk samples from goats and sheep in China [27]. In this study, A. ovis was detected in 79/552 (14.3\%) goats and sheep, and it was found in 11 of 24 counties studied. The positive rates of A. ovis were variable in goats and sheep, as well as between different geographical locations. These findings revealed that $A$. ovis is widely distributed in the sites investigated, implying that ovine anaplasmosis caused by A. ovis appears to be frequent in China.

Molecular characterization of Anaplasma has relied mainly on analyses of various gene loci [3]. The target genes used to determine the genetic diversity of $A$. ovis include the $16 S$ rRNA and msp 4 genes, and several genotypes and genetic variants have been identified in previous reports [22, 25, 28-32]. However, these molecular markers were found to be highly conserved and not informative enough to delineate $A$. ovis isolates $[3,13,22]$. In this study, we also found that the msp4 gene of $A$. ovis isolates identified from goats and sheep shared high sequence similarity $(99.8-100 \%)$, and were unable to reveal the genetic characterization of these isolates.

The major surface proteins of the members in the genus Anaplasma have been well characterized, especially in $A$. marginale and A. phagocytophilum [33, 34]. The Mspla has been extensively used as a molecular marker for characterizing A. marginale strains on the basis of the variable $\mathrm{N}$ terminal region, containing the repeated peptides [15]. To date, over 200 A. marginale Mspla tandem repeats have been identified, and a great number of strains from different countries have been classified into a variety of genotypes [3, $15,17]$. In this study, we examined $A$. ovis-positive samples for Mspla genotype, and 24 Mspla repeats with 33-47 amino acids, which corresponded to 19 A. ovis genotypes identified in goats and sheep in China. The structure of Mspla tandem repeat and the amino acid sequences vary among strains, which has also been shown for $A$. marginale.

It has been reported that the Mspla of A. marginale interact with vertebrate host and tick cells and have evolved on the strength of immune pressure [15]. This study revealed high genetic diversity of $A$. ovis isolates in small domestic ruminants in China, suggesting that msp1a gene of $A$. ovis may also have evolved more obviously than other genes. The A. ovis strains identified in this study had two to three Mspla repeats, some of which were shared between different strains. However, no significant association was observed between specific tandem repeats and host or geographical regions in this study, since some repeats were identified in both goats and sheep and distributed extensively (repeat Ao6, Ao8 and Ao10 identified in goats and sheep from several provinces). Moreover, same genotypes of $A$. ovis were found in several provinces (Ao1/Ao6, Ao2/Ao6, etc.); this may be attributed to the animal movement between those provinces.

To date, characterizing A. marginale strains based on MSP1a repeat sequences has been well studied. The present study, for the first time, revealed the genetic diversity of A. ovis using Mspla repeats in goats and sheep in China. Due to the wide distribution of $A$. ovis, more studies should be conducted in vertebrate and invertebrate hosts from different countries, which will ultimately 
Table 2 Organization of Msp1a repeats in A. ovis strains identified in goats and sheep. The structure of the Msp1a repeats region was represented using the repeat types showed in Fig. 1 for strains of $A$. ovis

\begin{tabular}{|c|c|c|c|c|c|}
\hline \multirow{2}{*}{$\begin{array}{l}\text { A. ovis strains } \\
\text { A7-1b, A7-12c, A7-20a, A7-20b }\end{array}$} & \multirow{2}{*}{$\begin{array}{l}\text { Origin } \\
\text { Hainan }\end{array}$} & \multirow{2}{*}{$\frac{\text { Host }}{\text { Goat }}$} & \multicolumn{3}{|c|}{ Structure of Mspla repeats } \\
\hline & & & Ao1 & Ao6 & \\
\hline$A 22-2 a, A 22-2 b, A 22-7 b$ & Yunnan & Goat & Ao1 & Ao6 & \\
\hline DSS5C, DSS16A, DSS16B & Guizhou & Goat & Ao1 & Ao6 & \\
\hline PZH41A, PZH41C & Sichuan & Goat & Ao1 & Ao6 & \\
\hline A22-7a & Yunnan & Goat & Ao2 & Ao6 & \\
\hline PZH46B, PZH46C, PZH60B, PZH60C & Sichuan & Goat & Ao2 & Ao6 & \\
\hline A7-1C & Hainan & Goat & Ao3 & Ao6 & \\
\hline PZH60A & Sichuan & Goat & Ao3 & Ao6 & \\
\hline A19-17a & Inner Mongolia & Sheep & Ao4 & Ao6 & \\
\hline A19-17b & Inner Mongolia & Sheep & Ao4 & Ao11 & \\
\hline DSS16C, DSS16D & Guizhou & Goat & Ao5 & Ao6 & \\
\hline A22-3a & Yunnan & Goat & Ao5 & Ao6 & \\
\hline A7-16a, A7-16b & Hainan & Goat & Ao7 & Ao6 & \\
\hline$A 18-32 b, A 18-32 c$ & Shanxi & Sheep & Ao9 & Ao10 & \\
\hline A7-17a, A7-17b & Hainan & Goat & Ao10 & A०8 & \\
\hline A18-3b, A18-6a, A18-6c & Shanxi & Sheep & Ao10 & Ao13 & \\
\hline A19-12a, A19-12b & Inner Mongolia & Sheep & Ao12 & A०8 & \\
\hline A19-1a, A19-1b & Inner Mongolia & Sheep & Ao14 & Ao8 & \\
\hline A8-105b & Inner Mongolia & Goat & Ao15 & Ao16 & \\
\hline $\mathrm{A} 18-7 \mathrm{~b}$ & Shanxi & Sheep & Ao17 & Ao6 & \\
\hline A18-18a & Shanxi & Sheep & Ao18 & Ao19 & Ao11 \\
\hline A18-32a & Shanxi & Sheep & Ao20 & Ao21 & \\
\hline$A 22-3 b$ & Yunnan & Goat & Ao22 & Ao6 & \\
\hline DSS25B & Guizhou & Goat & Ao23 & Ao10 & \\
\hline PZH41B & Sichuan & Goat & Ao24 & A05 & \\
\hline
\end{tabular}

provide more evolutionary and phylogenetic information about $A$. ovis strains.

\section{Conclusions}

Anaplasma ovis was molecularly detected in goats and sheep from 12 provinces in China, with an overall infection rate of $14.3 \%$. The $m s p 4$ gene of $A$. ovis had high sequence identity and was unable to be used to discriminate different strains. The Mspla could be used as a genetic marker for characterizing $A$. ovis, and 24 Msp1a repeats with 33-47 amino acids, which corresponded to 19 genotypes of $A$. ovis, were identified in goats and sheep in China. The present study provided the first evidence of genetic diversity of $A$. ovis based on the analyses of Mspla repeats.

\section{Additional file}

Additional file 1: Table S1. Partial mspla amino-acid sequences containing repeat sequences of $A$. ovis strains analyzed in this study. (DOCX $31 \mathrm{~kb}$ )

\section{Abbreviations}

Msp: Major surface protein; UV: ultraviolet

\section{Acknowledgements}

Not applicable.

\section{Funding}

This study was financially supported by the NSFC (31,502,091, 31,402,189, and 31,471,967); ASTIP, FRIP (2014ZL010), CAAS; NBCIS CARS-37; and the Jiangsu Co-Innovation Center Program for the Prevention and Control of Important Animal Infectious Diseases and Zoonoses, State Key Laboratory of Veterinary Etiological Biology Project.

\section{Availability of data and materials}

The datasets supporting the conclusions of this article are included within the article and its additional file. Sequences are submitted in GenBank database under accession numbers KY807127 and KY807128.

\section{Authors' contributions}

$\mathrm{HY}$ and $J \mathrm{~L}$ designed this study and critically revised the manuscript. $\mathrm{RH}, J Y$ $\mathrm{ZL}$ and SG participated in sample collection. RH, JY, QN, SG, MH and JL performed the experiments, data analysis, and drafted the manuscript. All authors read and approved the final manuscript. 


\section{Ethics approval and consent to participate}

This study was conducted in compliance with the Animal Ethics Procedures and Guidelines of the P. R. China, which has been approved by the Animal Ethics Committee of Lanzhou Veterinary Research Institute, Chinese Academy of Agricultural Sciences.

\section{Consent for publication}

Not applicable.

\section{Competing interests}

The authors declare that they have no competing interests.

\section{Publisher's Note}

Springer Nature remains neutral with regard to jurisdictional claims in published maps and institutional affiliations.

\section{Author details}

${ }^{1}$ State Key Laboratory of Veterinary Etiological Biology, Key Laboratory of Veterinary Parasitology of Gansu Province, Lanzhou Veterinary Research Institute, Chinese Academy of Agricultural Sciences, Xujiaping 1, Lanzhou, Gansu 730046, People's Republic of China. ${ }^{2}$ Qinghai Provincial Center for Animal Disease Control and Prevention, Xining 810003, Qinghai, People's Republic of China. ${ }^{3}$ Jiangsu Co-innovation Center for Prevention and Control of Important Animal Infectious Diseases and Zoonoses, Yangzhou 225009, People's Republic of China.

Received: 4 April 2017 Accepted: 5 September 2017

Published online: 29 September 2017

\section{References}

1. Rar V, Golovljova I. Anaplasma, Ehrlichia, and "Candidatus Neoehrlichia" bacteria: pathogenicity, biodiversity, and molecular genetic characteristics, a review. Infect Genet Evol. 2011;11:1842-61.

2. Theiler A. Gall-sickness of South Africa. (Anaplasmosis of cattle.). J Comp Pathol Ther. 1910;23:98-115.

3. Battilani M, De Arcangeli S, Balboni A, Dondi F. Genetic diversity and molecular epidemiology of Anaplasma. Infect Genet Evol. 2017:49:195-211.

4. Chen SM, Dumler JS, Bakken JS, Walker DH. Identification of a granulocytotropic Ehrlichia species as the etiologic agent of human disease. J Clin Microbiol. 1994;32:589-95.

5. Dumler JS, Barbet AF, Bekker CP, Dasch GA, Palmer GH, Ray SC, et al. Reorganization of genera in the families Rickettsiaceae and Anaplasmataceae in the order Rickettsiales: unification of some species of Ehrlichia with Anaplasma, Cowdria with Ehrlichia and Ehrlichia with Neorickettsia, descriptions of six new species combinations and designation of Ehrlichia equi and 'HGE agent' as subjective synonyms of Ehrlichia phagocytophila. Int J Syst Evol Microbiol. 2001;51:2145-65.

6. $L i \quad H$, Zheng $Y C, M a ~ L$, Jia $N$, Jiang $B G$, Jiang RR, et al. Human infection with a novel tick-borne Anaplasma species in China: a surveillance study. Lancet Infect Dis. 2015;15:663-70.

7. Renneker S, Abdo J, Salih DEA, Karagenc T, Bilgic H, Torina A, et al. Can Anaplasma ovis in small ruminants be neglected any longer? Transbound Emerg Dis. 2013;60:105-12.

8. Bevan LEW. Anaplasmosis of sheep. Vet J. 1912;68:400-1.

9. Li Y, Chen Z, Liu Z, Liu J, Yang J, Li Q, et al. Molecular survey of Anaplasma and Ehrlichia of red deer and sika deer in Gansu, China in 2013. Transbound Emerg Dis. 2016;63:e228-36.

10. Li Y, Chen Z, Liu Z, Liu J, Yang J, Li Q, et al. First report of Theileria and Anaplasma in the Mongolian gazelle, Procapra gutturosa. Parasit Vectors. 2014;7:614.

11. Chochlakis D, loannou I, Tselentis Y, Psaroulaki A. Human anaplasmosis and Anaplasma ovis variant. Emerg Infect Dis. 2010;16:1031-2.

12. Palmer GH, Abbott JR, French DM, McElwain TF. Persistence of Anaplasma ovis infection and conservation of the msp-2 and msp-3 multigene families within the genus Anaplasma. Infect Immun. 1998;66:6035-9.

13. de la Fuente J, Atkinson MW, Naranjo V, Fernandez de Mera IG, Mangold AJ, Keating KA, Kocan KM. Sequence analysis of the msp4 gene of Anaplasma ovis strains. Vet Microbiol. 2007;119:375-81.

14. Cabezas-Cruz A, de la Fuente J. Anaplasma marginale major surface protein 1a: a marker of strain diversity with implications for control of bovine anaplasmosis. Ticks Tick Borne Dis. 2015;6:205-10.
15. de la Fuente J, Lew A, Lutz H, Meli ML, Hofmann-Lehmann R, Shkap V, et al. Genetic diversity of Anaplasma species major surface proteins and implications for anaplasmosis serodiagnosis and vaccine development. Anim Health Res Rev. 2005;6:75-89.

16. Cabezas-Cruz A, Passos LM, Lis K, Kenneil R, Valdes JJ, Ferrolho J, et al. Functional and immunological relevance of Anaplasma marginale major surface protein 1a sequence and structural analysis. PLoS One. 2013;8: e65243.

17. Khumalo ZTH, Catanese HN, Liesching N, Hove P, Collins NE, Chaisi ME, et al. Characterization of Anaplasma marginale subsp. centrale strains by use of msp1aS genotyping reveals a wildlife reservoir. J Clin Microbiol. 2016;54: 2503-12.

18. Ma M, Liu Z, Sun M, Yang J, Guan G, Li Y, et al. Development and evaluation of a loop-mediated isothermal amplification method for rapid detection of Anaplasma ovis. J Clin Microbiol. 2011:49:2143-6.

19. de la Fuente J, Torina A, Caracappa S, Tumino G, Furla R, Almazan C, Kocan KM Serologic and molecular characterization of Anaplasma species infection in farm animals and ticks from Sicily. Vet Parasitol. 2005;133:357-62.

20. Yang J, Li Y, Liu Z, Liu J, Niu Q, Ren Q, et al. Molecular detection and characterization of Anaplasma spp. in sheep and cattle from Xinjiang, northwest China. Parasit Vectors. 2015;8:108.

21. Friedhoff KT. Tick-borne diseases of sheep and goats caused by Babesia, Theileria or Anaplasma spp. Parassitologia. 1997;39:99-109.

22. Liu Z, Luo J, Bai Q, Ma M, Guan G, Yin H. Amplification of 165 rRNA genes of Anaplasma species in China for phylogenetic analysis. Vet Microbiol. 2005:107:145-8

23. Lu WS, Lu WX, Zhang QC, Yu F, Dou HF, Yin H. Ovine anaplasmosis in northwest China. Trop Anim Health Pro. 1997;29:16-8.

24. Zhang Y, LV Y, Zhang F, Zhang W, Wang J, Cui Y, et al. Molecular and phylogenetic analysis of Anaplasma spp. in sheep and goats from six provinces of China. J Vet Sci. 2016;17:523-9.

25. Liu Z, Ma M, Wang Z, Wang J, Peng Y, Li Y, et al. Molecular survey and genetic identification of Anaplasma species in goats from central and southern China. Appl Environ Microbiol. 2012;78:464-70.

26. Cui Y, Yan Y, Wang X, Cao S, Zhang Y, Jian F, et al. First molecular evidence of mixed infections of Anaplasma species in dogs in Henan, China. Ticks Tick Borne Dis. 2017:8:283-9.

27. Zhang Y, Lv Y, Cui Y, Wang J, Cao S, Jian F, et al. First molecular evidence for the presence of Anaplasma DNA in milk from sheep and goats in China. Parasitol Res. 2016;115:2789-95.

28. de la Fuente J, Atkinson MW, Hogg JT, Miller DS, Naranjo V, Almazan C, et al. Genetic characterization of Anaplasma ovis strains from bighorn sheep in Montana. J Wildl Dis. 2006;42:381-5.

29. Hornok S, Elek V, de la Fuente J, Naranjo V, Farkas R, Majoros G, Foldvari G. First serological and molecular evidence on the endemicity of Anaplasma ovis and A. marginale in Hungary. Vet Microbiol. 2007:122:316-22.

30. Torina A, Alongi A, Naranjo V, Scimeca S, Nicosia S, Di Marco V, et al. Characterization of Anaplasma infections in Sicily, Italy. Ann NY Acad Sci. 2008;1149:90-3.

31. Torina A, Alongi A, Naranjo V, Estrada-Pena A, Vicente J, Scimeca S, et al. Prevalence and genotypes of Anaplasma species and habitat suitability for ticks in a Mediterranean ecosystem. Appl Environ Microbiol. 2008;74:7578-84.

32. Zobba R, Anfossi AG, Pinna Parpaglia ML, Dore GM, Chessa B, Spezzigu A, et al. Molecular investigation and phylogeny of Anaplasma spp. in Mediterranean ruminants reveal the presence of neutrophil-tropic strains closely related to A. platys. Appl Environ Microbiol. 2014;80:271-80.

33. Lin MQ, Kikuchi T, Brewer HM, Norbeck AD, Rikihisa Y. Global proteomic analysis of two tick-borne emerging zoonotic agents: Anaplasma phagocytophilum and Ehrlichia chaffeensis. Front Microbiol. 2011:2:24.

34. Brayton KA, Kappmeyer LS, Herndon DR, Dark MJ, Tibbals DL, Palmer GH, et al. Complete genome sequencing of Anaplasma marginale reveals that the surface is skewed to two superfamilies of outer membrane proteins. Proc Natl Acad Sci USA. 2005;102:844-9. 